\title{
APLICAÇÃO DE DIFERENTES DOSAGENS DE ESTERCO DE GALINHA NO SUBSTRATO PARA PRODUÇÃO DE MUDAS DE MELÃO
}

\author{
Eduardo Henrique Lima Mazzuchelli; Rita de Cássia Lima Mazzuchelli; Pedro Veridiano Baldotto \\ Universidade do Oeste Paulista - UNOESTE, Curso de Mestrado em Agronomia, Presidente Prudente - SP. E-mail: \\ eduardomazzuchelli@yahoo.com.br
}

\section{RESUMO}

O objetivo do presente trabalho foi o de avaliar a produção de mudas de melão (Cucumis melo L.) em função de dosagens de esterco de galinha adicionadas ao substrato. O experimento foi conduzido em casa de vegetação localizada no Campus II da Universidade do Oeste Paulista (UNOESTE) - Faculdade de Ciências Agrárias, em Presidente Prudente - SP, nos meses de março a abril de 2014. Para o desenvolvimento do experimento foi utilizado o substrato comercial Bioplant ${ }^{\circledR}$, para o preenchimento de bandejas de poliestireno expandido com 200 células. Os tratamentos foram constituídos com adições crescentes de esterco de galinha curtido ao substrato, com as dosagens de $0 ; 2 ; 4 ; 8$ e $12 \%$ do substrato comercial, correspondentes a 0; 0,5; 1,$0 ; 2,0 ; 3,0 \mathrm{~kg}$ em $25 \mathrm{~kg}$ do substrato Bioplant ${ }^{\circledR}$. Os tratamentos foram utilizados para preencher alternadamente as fileiras da bandeja, totalizando cinco bandejas. Em cada célula foram adicionadas duas sementes de melão, cultivar Redondo Gaúcho. As mudas foram mantidas por 15 dias em estufa, recebendo irrigação periódica. Foram avaliadas, número de folhas por muda, massa fresca da parte aérea da muda, massa fresca do sistema radicular, comprimento da parte aérea e comprimento do sistema radicular. Os dados obtidos foram submetidos à análise de variância através do programa SISVAR (FERREIRA, 2008). Para avaliar as doses de esterco de galinha sendo aplicada a regressão polinomial para o ajuste das equações. A adição da dosagem de $4 \%$ do esterco de galinha ao substrato comercial para a produção de mudas de melão foi mais eficiente, resultado em mudas com maior desenvolvimento.

Palavras-chave: Cucumis melo L., matéria orgânica, substrato, sustentabilidade.

\section{APLICATION OF DIFFERENT DOSAGES OF chicken manure ON SUBSTRACT TO PRODUCTION OF MELON SEEDLINGS}

\begin{abstract}
The aim of this study was to evaluate the production of seedlings of melon (Cucumis melo L.) as a function of doses of chicken manure added to the substrate. The experiment was conducted in a greenhouse located in the Campus II of the Universidade do Oeste Paulista (UNOESTE) - Faculty of Agricultural Sciences, in Presidente Prudente - SP, in the months from March to April 2014 for the development of the experiment the substrate was used commercial Bioplant ${ }^{\circledR}$, to fill expanded polystyrene trays with 200 cells. Treatments were with increasing additions of manure tanned chicken to the substrate, with the levels of $0 ; 2 ; 4 ; 8$ and $12 \%$ of the commercial substrate, corresponding to $0 ; 0.5 ; 1.0 ; 2.0 ; 3.0 \mathrm{~kg} 25$ kg Bioplant ${ }^{\circledR}$ substrate. The treatments were used to alternately fill the ranks of the tray, totaling five trays. In each cell were added two melon seeds, cultivate Redondo Gaucho. The seedlings were kept in a greenhouse for 15 days, receiving regular irrigation. , Number of leaves per seedling fresh weight of the aerial part of the seedling, fresh root weight, shoot length and root length were evaluated. Data were subjected to analysis of variance using the program SISVAR (FERREIRA, 2008). To evaluate the doses of chicken manure polynomial
\end{abstract}


regression to fit equations being applied. The addition of the dosage of $4 \%$ of chicken manure to commercial substrate for the production of seedlings of melon was more efficient, result in seedlings with greater development.

Keywords: Cucumis melo L., organic matter, substrate, sustainability.

\section{INTRODUÇÃO}

A cultura do meloeiro apresenta grande importância para o agronegócio brasileiro, por se tratar de uma fruta apreciada pelo seu gosto e aroma característico, sendo consumida em todo o país, pode ser consumida na forma in natura, ou na forma de sucos.

O melão é uma cultura de clima tropical, portanto se desenvolve melhor em regiões de clima mais quente, com alta insolação e baixa umidade relativa do ar, sendo assim esta cultura acaba se desenvolvendo melhor na região Nordeste do país.

Um recurso que cada vez mais está ganhando espaço entre as técnicas utilizadas na produção de mudas das mais diversas hortaliças é a combinação de dois ou mais substratos. Este recurso permite reaproveitar dejetos que seriam descartados da produção animal ou vegetal, incorporando esta matéria orgânica, rica em macro e micronutrientes, ao substrato comercial ou mesmo o próprio solo, havendo uma economia para o produtor rural, por se tratar de reaproveitamento de dejetos, e uma prática sustentável, já que otimiza a utilização de matéria orgânica, sem agredir o meio ambiente.

O esterco de galinha é uma ótima fonte de nutrientes, possui uma alta concentração de nutrientes mesmo em pequenas porções de esterco, se comparado a outros tipos, como o de gado, por exemplo, enriquecendo assim a mistura com o substrato comercial e sendo uma pratica economicamente viável ao produtor de mudas, já que reaproveita o dejeto da produção de aves, e disponibiliza diversos macro e micronutrientes ao substrato utilizado na produção das mudas, o que diretamente interferirá no vigor e qualidade da muda, sendo um fator exponencial a planta adulta no campo ou estufa.

O substrato enriquecido com o esterco de galinha, ainda adquire outras características de um bom substrato para mudas de hortaliças, como a capacidade de retenção e absorção de água, devido aos coloides da matéria orgânica, condições de aeração as raízes, capacidade de disponibilização imediata de macro e micronutrientes, isenção de patógenos e organismos saprófitas além de ser considerado leve.

O objetivo do presente trabalho foi o de avaliar a produção de mudas de melão (Cucumis melo L.) em função de dosagens de esterco de galinha adicionadas ao substrato. 


\section{METODOLOGIA}

O experimento foi conduzido em casa de vegetação localizada no Campus II da Universidade do Oeste Paulista (UNOESTE) - Faculdade de Ciências Agrárias, em Presidente Prudente - SP, nos meses de março a abril de 2014. As coordenadas do local são latitude de $22^{\circ} 07^{\prime} 04^{\prime \prime}$ e longitude de $51^{\circ} 22^{\prime} 04^{\prime \prime}$ e altitude de aproximadamente 432 metros acima do nível do mar.

O clima da região é pela classificação de Köppen Aw como mesotérmico com verões quentes e período chuvoso bem definido nos meses de setembro a março e invernos secos com temperaturas mais amenas nos meses de abril a setembro.

Para o desenvolvimento do experimento foi utilizado o substrato comercial Bioplant ${ }^{\circledR}$, para o preenchimento de bandejas de poliestireno expandido com 200 células.

Os tratamentos foram constituídos com adições crescentes de esterco de galinha curtido ao substrato, com as dosagens de $0 ; 2 ; 4 ; 8$ e $12 \%$ do substrato comercial, correspondentes a 0; 0,$5 ; 1,0 ; 2,0 ; 3,0$ kg em 25 kg do substrato Bioplant ${ }^{\circledR}$.

Os tratamentos foram utilizados para preencher alternadamente as fileiras da bandeja, totalizando cinco bandejas.

Em cada célula foram adicionadas duas sementes de melão, cultivar Redondo Gaúcho da empresa Horticeres ${ }^{\circledR}$.

As mudas foram mantidas por 15 dias em estufa, recebendo irrigação periódica. Após este período foram retiradas cinco mudas aleatoriamente de cada bandeja de cada tratamento para as análises:

a) Número de folhas por muda, considerando-se todas as folhas que apresentam tamanho mínimo superior a $1,0 \mathrm{~cm}$;

c) Massa fresca da parte aérea da muda, aferido após o corte rente ao substrato;

d) Massa fresca do sistema radicular da muda, após a remoção do substrato aderido as raízes;

e) Comprimento da parte aérea da muda, com auxílio de régua;

f) Comprimento do sistema radicular da muda, com auxílio de régua;

Os dados obtidos foram submetidos à análise de variância através do programa SISVAR (FERREIRA, 2008). Para avaliar as doses de esterco de galinha sendo aplicada a regressão polinomial para o ajuste das equações. 


\section{RESULTADOS}

Podemos observar (Figura 01) que os tratamentos efetuados com a adição de esterco de galinha ao substrato para produção de mudas de melão respondeu positivamente até a dosagem de 4\%, acima desta dosagem houve um declínio em relação ao tamanho das mudas.

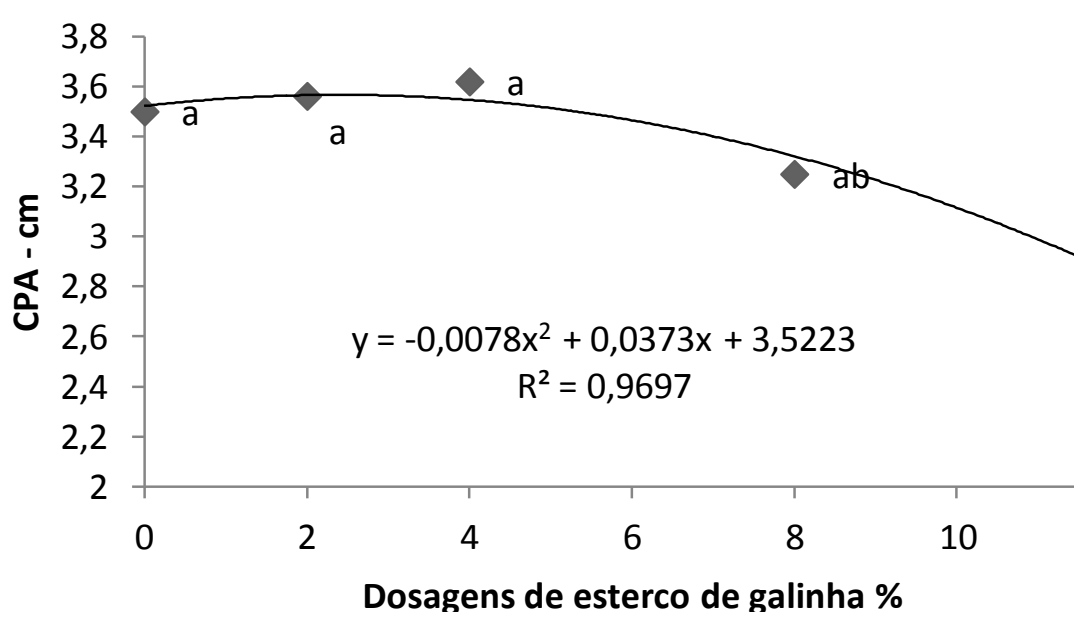

Figura 01. Comprimento da parte aérea (CPA $-\mathrm{cm}$ planta $\left.^{-1}\right)$ das mudas de melão submetidas a dosagens crescentes de esterco de galinha ao substrato.

O número de folhas das mudas de melão não apresentou diferenças significativas entre os tratamentos, porém, houve uma tendência de aumento na dosagem de $4 \%$ e após esta dosagem os tratamentos começaram a decrescer no número de folhas (Figura 02).

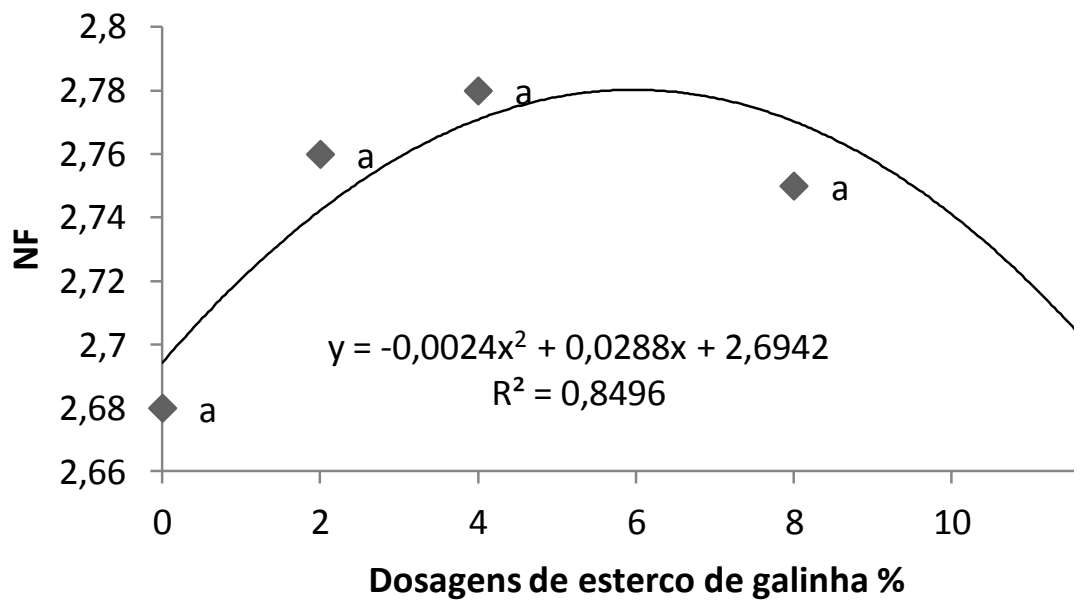

Figura 02. Número de folhas (NF planta ${ }^{-1}$ ) das mudas de melão submetidas a dosagens crescentes de esterco de galinha ao substrato. 
Na Figura 03, em relação ao comprimento do sistema radicular das mudas, podemos observar que o tratamento com a adição de $4 \%$ de esterco de galinha no substrato para a produção de mudas de melão proporcionou maior desenvolvimento do sistema radicular, após esta dosagem começou a haver um declínio do sistema radicular das mudas.

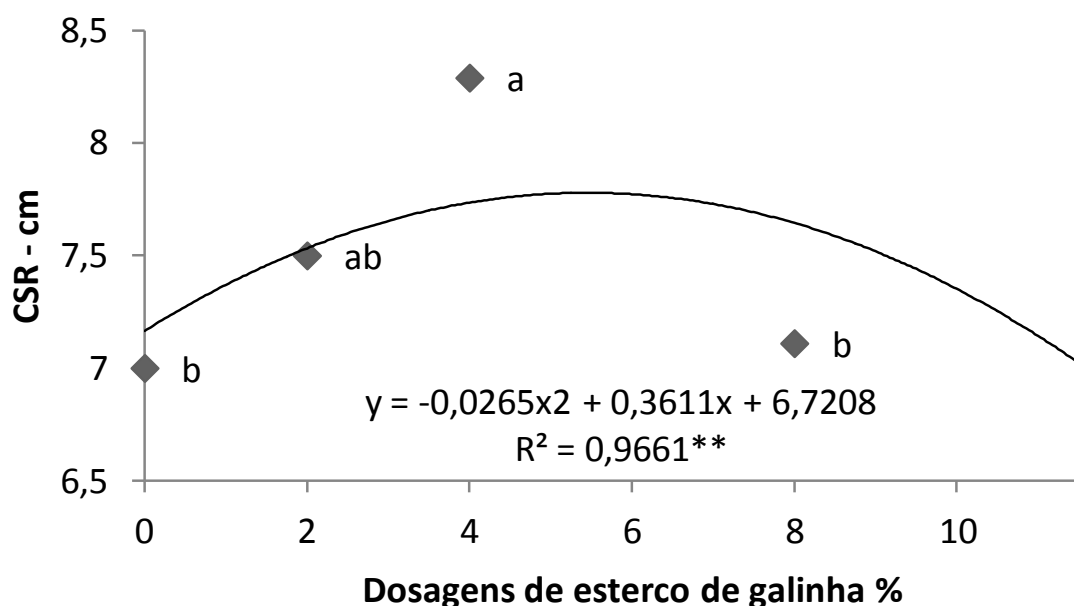

Figura 03. Comprimento do sistema radicular (CSR $-\mathrm{cm}$ planta $\left.{ }^{-1}\right)$ das mudas de melão submetidas a dosagens crescentes de esterco de galinha ao substrato.

Na avaliação da massa fresca da parte aérea das mudas de melão todos os tratamentos efetuados apresentaram incrementos no desenvolvimento da parte aérea, diferindo do tratamento controle, sem a adição de esterco de galinha ao substrato (Figura 04). Entre os tratamentos efetuados, a adição de $4 \%$ apresentou uma tendência de maior resposta na parte aérea das mudas.

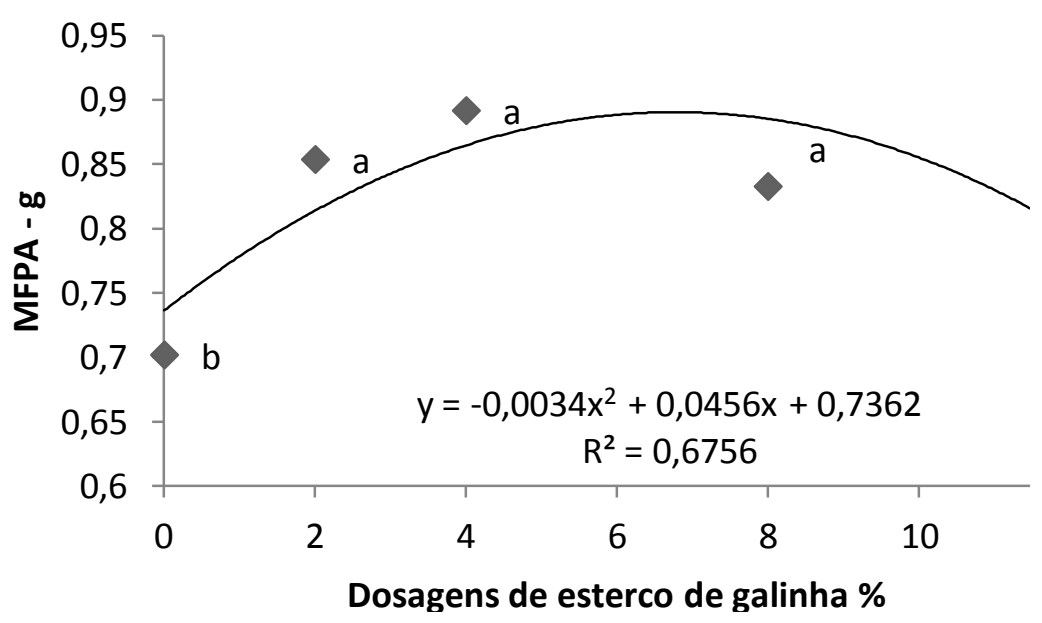

Figura 04. Massa fresca da parte aérea (MFPA - gramas planta ${ }^{-1}$ ) das mudas de melão submetidas a dosagens crescentes de esterco de galinha ao substrato. 
A resposta da massa fresca do sistema radicular das mudas de melão, indicou que todos os tratamentos realizados apresentaram maior desenvolvimento do sistema radicular, diferindo do tratamento controle, sem a adição de esterco de galinha ao substrato (Figura 05).

Sendo que próximo a dosagem de $4 \%$ houve maior desenvolvimento das raízes das mudas de melão.

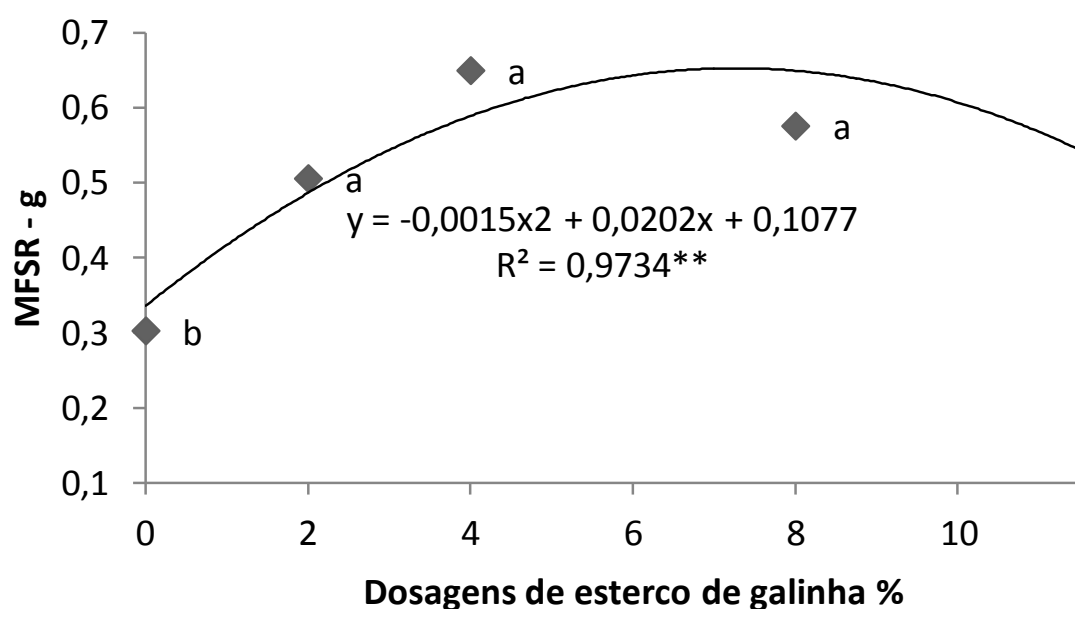

Figura 05. Massa fresca do sistema radicular (MFSR - gramas planta ${ }^{-1}$ ) das mudas de melão submetidas a dosagens crescentes de esterco de galinha ao substrato.

\section{DISCUSSÃO}

O cultivo das hortaliças requer cada vez mais cuidado e atenção em todas as etapas produtivas, as sementes que anteriormente eram depositadas diretamente no canteiro produtivo, passam a ser confeccionadas mudas, com o objetivo de melhorar, antecipar o ciclo produtivo. As sementes de hortaliças apresentam grande valor, portanto, o agricultor não pode desperdiçá-las, e devem possibilitar condições de um melhor desenvolvimento das mudas, para o maior sucesso quando transferidas para o local de cultivo definitivo (SEABRA JÚNIOR, et al., 2004; CAÑIZARES et al., 2002).

Almeida (2013) observou em geral, que para produção de mudas de melancia, das cultivares Crimson Select Plus e Charleston Gray a dose de composto orgânico que apresentou os melhores resultados para todas as variáveis analisadas foi à dose de $50 \%$ do composto ao substrato.

Os trabalhos com o desenvolvimento de mudas de melancia com diferentes substratos e formulações minerais. A maioria deles, são incorporados aos substratos nutrientes minerais, visando a suprir a demanda das plantas (MOTA et al., 2011). 
Araujo et al. (2013) estudando diferentes substratos para a cultura do melão observaram que os melhores resultados encontrados para todas as variáveis estudadas foram resultantes da composição do substrato composto por proporções equivalentes de húmus de minhoca e solo.

\section{CONCLUSÃO}

A adição da dosagem de $4 \%$ do esterco de galinha ao substrato comercial para a produção de mudas de melão foi mais eficiente, resultado em mudas com maior desenvolvimento.

\section{REFERÊNCIAS}

ALMEIDA, R. A. Aspectos germinativos de duas cultivares de melancia em diferentes doses de composto orgânico. Trabalho de conclusão de curso. Universidade Estadual da Paraíba. 2013.

ARAÚJO, D. D.; MAIA JUNIOR, S. O.; SILVA, S. F.; ANDRADE, J. R.; ARAÚJO, D. L. Produção de mudas de melão cantaloupe em diferentes tipos de substratos. Revista Verde de Agroecologia e Desenvolvimento Sustentável, v. 8, n. 3, p. 15-20, 2013.

BEZERRA, F. C. Produção de mudas de hortaliças em ambiente protegido. Fortaleza: Embrapa agroindústria tropical, 2003. 19 p. (Documento, 72).

BRAGA SOBRINHO, R.; GUIMARÃES, J.A.; FREITAS, J.A.D.; TERÃO, D. Produção integrada de melão. Fortaleza: Embrapa Agroindústria Tropical, 2008. 338p.

CAÑIZARES, K.A.; COSTA, P.C.; GOTO, R.; VIEIRA, A.R.M. Desenvolvimento de mudas de pepino em diferentes substratos com e sem uso de solução nutritiva. Horticultura Brasileira, Brasília, v. 20, n. 2, p.227-229, junho 2002. http://dx.doi.org/10.1590/S0102-05362002000200022

CARVALHO, J. M. Comercialização de frutas de qualidade: a importância do tratamento póscolheita. 1996. 176 p. Dissertação Mestrado - Universidade Federal de Lavras, Lavras, 1996.

DANTAS, I. C.; OLIVEIRA, C. W.; SILVA, F. L.; SANTOS, F. S. S.; MARCO, C. A. Produção de melão amarelo sob diferentes densidades de plantio.Revista Brasileira de Agricultura Irrigada-Rbai, v. 7, n. 1, p. $74-84,2013$. http://dx.doi.org/10.7127/rbai.v7n100098

FERNANDES, O.B.; PEREIRA, F.H.F.; ANDRADE JÚNIOR, W.P.; QUEIROGA, R.C.F.; QUEIROGA, F.M. Efeito do nitrato de cálcio na redução do estresse salino no meloeiro. Revista Caatinga, Mossoró, v. 23, n. 3, p. 93-103, 2010.

FERREIRA, D. F. SISVAR: Programa para análises e ensino de estatística. Revista Symposium, v. 6, p. 36-41, 2008.

FILGUEIRA, F.A.R. Novo manual de olericultura: agroecologia moderna na produção e comercialização de hortaliças. 3aed. revista e ampliada. Viçosa: UFV, 2009. 421p. 
IBGE. Instituto Brasileiro de Geografia e Estatística. 2008. 6 de janeiro. Indicadores conjunturais: produção agrícola/agricultura. Disponível em: <http://www.ibge.gov.br/>. Acesso em: 22 abr. 2014.

MOTA, A. F.; ALMEIDA, J. P. N.; SANTOS, J. S.; AZEVEDO, J.; GURGEL, M. T. Desenvolvimento inicial de mudas de melancia 'crimson sweet' irrigadas com águas residuárias. Revista Verde (Mossoró RN - Brasil) v.6, n.2, p. $98-104$ abril/junho de 2011.

QUEIROGA, F. M. D.; NOVO JUNIOR, J.; COSTA, S. Â. D. D.; OLIVEIRA FILHO, F. D. S.; PEREIRA, F. H. F.; SOUZA FILHO, A. L. D.; MARACAJA, P. B. Produção e qualidade de frutos de melão Harper em função de doses de boro. Agropecuária Científica no Semiarido, v. 9, n.3, p.87-93. 2013

PELIZZA, T. R. et al. Produção de mudas de meloeiro amarelo, sob cultivo protegido, em diferentes substratos. Revista Ceres, v. 60, n. 2, p. 257-261, 2013. http://dx.doi.org/10.1590/S0034737X2013000200015

PIRES, M. M. M.L.; SANTOS, H. A.; SANTOS, D. F.; VASCONCELOS, A. S.; ARAGÃO, C. A. 2013. Produção do meloeiro submetido a diferentes manejos de água com o uso de manta de tecido não tecido. Horticultura Brasileira, v. 31 p.304-310. http://dx.doi.org/10.1590/S010205362013000200021

SEABRA JÚNIOR, S.; GADUN, J.; CARDOSO, A.I.I. Produção de pepino em função da idade das mudas produzidas em recipientes com diferentes volumes de substrato. Horticultura Brasileira, Brasília, v.22, n.3, p.610-613, jul-set 2004. http://dx.doi.org/10.1590/S0102-05362004000300022

SENHOR, R. F. Epidemiologia da podridão-de-cratera em frutos de meloeiro. 2006. $76 \mathrm{f}$. Dissertação (Mestrado em Fitossanidade) - Universidade Federal Rural de Pernambuco, Recife, 2006.

SILVA, J. L. A. et al. Influência da água residuária de origem doméstica no crescimento inicial do melão ‘amarelo ouro'. Agropecuária Científica no Semiarido, v. 8, n. 4, p. 16-22, 2012.

SOARES, C. A.; JÚNIOR, A. F. R.; SILVA, N. S.; MOUSINHO, F. E. P.; ZANINI, J. R. Função de resposta do meloeiro à aplicação de doses de adubação nitrogenada para dois níveis de irrigação em Teresina, PI. Comunicata Scientiae, v. 4, n. 4, p. 391-400, 2013. 